me, but on the other hand I am very familiar with the article in the "Dictionary of National Biography", which is from the same hand-that of Mr. Herbert Rix. The latter article, which cites Oldenburg's "peculiar temper", and his draft petition for a patent for Huygens' watch, has contributed to form my unfavourable opinion of Oldenburg's character. It further points out that Oldenburg first enthusiastically urged Spinoza to publish his writings, and afterwards withdrew. I have now read the NATURE article, and do not find that it runs counter to my views. Rix calls Oldenburg "an interesting man who lived in a most interesting period", and opines that without his endeavours, and those of Hooke, the Society would scarcely have held together, with all of which Mr. James and I will both agree. So far as I can see, there is nothing that shows any particular sympathy with Oldenburg's personal character, and Mr. Rix's other article, which was published two years later, and must represent his considered opinion, seems to me definitely unfavourable.

Hooke's character was manifestly imperfect, but he had the excuses of genius and chronic illness, neither of which can be advanced for Oldenburg. I was concerned not so much to estimate Oldenburg, who was, after all, a very second-rate intellect ("His scientific observations were certainly very mixed, many of them trivial, and some of them superstitious," says Mr. Rix), but rather to point out that Hooke had just cause to complain of him. I agree with Prof. More, where he refers to Hooke "showing the contrast of an essentially noble character in large matters with an irritable, suspicious and cynical temperament in the familiar affairs of life", and I am of the opinion that Oldenburg did much to embitter Hooke's character and to bring into prominence his weaker points. If all that can be done to shake my views as to Oldenburg's character is to refer to an article which stresses his undoubted industry and vast correspondence, and to sneer at Hooke's private record as "lavender entries", I shall continue in my error.

So far as I know, the Diary which Dr. Gunther has transcribed had not been published when I wrote the article in question. This alone is sufficient to account for my not having read it. I may add that Waller himself says "the greater part of my Vouchers have been either taken out of his own Memorials or from the Journals of the Royal Society", and although it is clear from his biography of Hooke that he had spoken with his subject on more than one occasion, there is nothing in it that bespeaks intimacy.

As regards the general question of a portrait, although none has survived, it seems probable from the Diary which I reviewed that one was made, for on October 16, 1674, we read " $\mathrm{Mr}$. Bonust drew picture", and on December 24 of the same year, "The workmen left work did nothing but get together my picture frame". The painter, of whom it is earlier recorded "Mr. Janeway sat for picture to Mr. Bonus", was, according to Mr. Robinson's editorial note, probably Bownest, who painted portraits, principally of dissenting ministers. Perhaps, then, there is a portrait somewhere in existence.

\footnotetext{
Physics Laboratory, University College, London, W.C.1. Sept. 21.
}

E. N. da C. Andrade.

\section{The Meaning of Probability}

I sugGest that Dr. Dingle's problem in his article in NaTuRE of September 14, p. 423, is not quite fairly stated. If Ohm's law has been found true in 9,999 cases and found false in one case, and if $P$ who speaks truth once in 10,000 times says he has found it true, it is equally probable that he has struck the exceptional case and told the normal lie, or struck the normal case and told the exceptional truth. If this is not immediately clear, it becomes so on considering $10^{8}$ experiments by $P$, assuming, as is proper, that the exceptional case occurs once in 10,000 times throughout. In this sense, the probability that $P$ has found the law false is one half.

Fuglestemmen,
Layters Way,
Gerrards Cross,
Bucks.
Sept. 16.

IN his article on 'The Meaning of Probability' in NATURE of September 14, Dr. Dingle has attempted to support his case by means of a striking example. Unfortunately his illustration is by no means happily chosen, and the issue may be further confused by his treatment of it in a way no one is likely to defend. When the truth (by which we do not mean the whole truth and nothing but the truth) of Ohm's law is in question, only evidence arising from experimental investigations is pertinent; no statement, independent of experimental work, by any individual, whatever his habit regarding the truth, is of value. On the data given, the probability that the law will be found to hold in a new experiment is therefore $9,999 / 10,000$.

For the purpose of the discussion, Ohm's law must be replaced by a question in which individual testimony constitutes relevant evidence. If we then waive the debatable point of attaching any value whatever to the statement of so notoriously untruthful an individual, we cannot reach the probability $\frac{1}{2}$ put forward by Dr. Dingle. Each statement, like each experimental inquiry, has to be regarded as a separate item of evidence. In the absence of qualifying evidence, each is to be given equal weight. Dr. Dingle, on the other hand, invites us to regard the combined results of 10,000 experiments as no more than equal in weight to a single statement made by a confirmed liar. It is obvious that we exaggerate the effect of this statement on the probability if we replace it by an additional experiment unfavourable to the law. The probability, then, so far from falling from $9,999 / 10,000$ to $\frac{1}{2}$, certainly does not fall as far as 9,999/10,001. The ratio which would result from the given figures by simple enumeration is, in a suitable problem, $9,999 \cdot 0001 / 10,001$.

It may be observed that the fractional part of the numerator would not become zero, even if the data were strengthened to the extent that the individual concerned had never been known to tell the truth.

$$
\begin{gathered}
\text { National Physical Laboratory, } \\
\text { Teddington. } \\
\text { Sept. } 17 .
\end{gathered}
$$

T. SмrTH.

A suFfiCIENTLY general statement of the problem I was trying to exemplify is as follows:-If we have two independent sources of information $(\beta$ and $\gamma$ ) bearing on the question of the truth or falsehood of a proposition 